\title{
Digitizer Device
}

National Cancer Institute

\section{Source}

National Cancer Institute. Digitizer Device. NCI Thesaurus. Code C49921.

A device designed to convert analog signal to digital signal. 